\title{
RETORNO MIGRATORIO DESDE ESPAÑA: UN FLUJO VARIABLE Y COMPLEJO
}

\section{MIGRATORY RETURN FROM SPAIN: A VARIABLE AND COMPLEX FLOW}

Rosa Resino García*, Beatriz Cristina Jiménez Blasco**

Mercedes Arranz Lozano***

Resumen: Los movimientos migratorios de retorno desde España están sufriendo cambios significativos en la última década. Este trabajo analiza la situación actual tras el llamado boom de los retornos durante los años más duros de la crisis. La metodología utilizada combina el análisis cuantitativo de los datos estadísticos con técnicas cualitativas que ayudan a interpretar las cifras y a indagar en las causas que llevan a los inmigrantes al retorno o, por el contrario, a permanecer en España. El análisis e interpretación de la evolución cambiante de los saldos migratorios exteriores recientes, tanto en los países de destino como en las comunidades autónomas de origen constituyen la aportación principal de la investigación.

Palabras clave: retorno migratorio; inmigración y crisis económica; arraigo.

* Departamento de Geografía. Universidad Complutense de Madrid. r.resino@ghis.ucm.es.

** Departamento de Geografía Universidad Complutense de Madrid. bcjimene@ghis.ucm.es

*** Departamento de Geografía. Universidad de La Laguna. marranzl@ull. edu.es 
Abstract: Return migratory movements from Spain are undergoing significant changes in the last decade. This work analyzes the current fluctuating trajectory that is taking place after the so-called 'boom of returns' during the hardest years of the crisis. The methodology used combines the quantitative analysis of statistical data with qualitative techniques that help to interpret the figures and to investigate the causes that lead immigrants to return or, conversely, to remain in Spain. The main contribution of the research is the analysis and interpretation of the changing evolution of recent foreign migration balances, both in the countries of destination and in the autonomous communities of origin.

Key words: migratory return; immigration and economic crisis; settlement.

\section{INTRODUCCIÓN}

En los últimos años la opinión pública española ha mostrado un creciente interés sobre el retorno migratorio a partir de las informaciones que los medios de comunicación han difundido sobre el regreso de muchos inmigrantes a sus lugares de origen, como consecuencia de los efectos de la crisis económica (Medina, Herrarte y Vicens, 2010). Paralelamente, investigadores sociales de diversos campos (Iglesias, 2012; Cassarino, 2013; Jauregui y Recaño, 2014; López de Lera, Pérez Caramés, 2015; entre otros) han abordado este fenómeno desde diferentes ópticas científicas.

Durante las dos últimas décadas del siglo $\mathrm{XX}$ y primera del XXI, no se prestó apenas atención a las corrientes de retorno, pues, aunque fueran mucho menores que las emigratorias, siempre ha existido una cierta proporción de inmigrantes que no logran establecerse en el país de destino y retornan o emigran a terceros países durante el primer año de residencia en el país de destino (Gmelch, 1980). A partir del estallido de la burbuja inmobiliaria, que afectó claramente a la capacidad de ahorro y envío de dinero de los inmigrantes, e incluso llegando a tener dificultades para permanecer en España (Martín Ruiz, 2009; Cebrián de Miguel, Bodega, MartínLou y Guajardo, 2010), el retorno migratorio cobró una relevancia mayor en la investigación social. 
Entre los motivos que llevan a la decisión del retorno migratorio se entremezclan factores personales, con otros ligados al empeoramiento de la situación económica de las sociedades receptoras (Bastia, 2011), así como a la mejora que pueda haberse producido en los países de origen durante los años de permanencia en España del migrante (García Ballesteros, Jiménez Blasco y Mayoral, 2014). Por lo tanto, la toma de decisiones se fundamenta en factores estructurales, por un lado, y motivaciones individuales y familiares, por otro (López de Lera y Pérez Caramés, 2015).

Esta investigación se propone como objetivo principal evaluar el volumen real de retornados y analizar los cambios en la evolución del retorno migratorio desde España en los últimos años, con el fin de explicar la cambiante trayectoria de este tipo de flujos. Por otra parte, el trabajo pretende dar respuesta tanto a las causas del retorno como a las de la permanencia, aun en los casos de manifiesta precariedad.

\section{APROXIMACIÓN A LAS INTERPRETACIONES TEÓRICAS SOBRE EL RETORNO MIGRATORIO}

Sin duda la migración de retorno es un componente esencial de los movimientos migratorios, estando ya presente en las leyes enunciadas a finales del siglo XIX por Ravenstein (Arango, 1985). El deseo de volver al país de origen se ha considerado tradicionalmente como algo inherente al fenómeno de la migración (Fuente, 2003). En principio, el retorno indica que el proceso migratorio no era definitivo, la idea de regreso al lugar de origen es algo habitual en los procesos migratorios internacionales (Izquierdo y Martínez-Buján, 2014). Pero en cualquier tipo de retorno la vuelta al lugar de origen no suele ser fácil, de forma que se puede considerar, como dicen Varona y Daolio (1995) que "retornar es como emigrar dos veces".

Son diversas las interpretaciones teóricas que se han dado al retorno voluntario de inmigrantes. Gmelch (1980) en su clásico estudio puso de relieve el carácter descriptivo de la mayoría de las investigaciones sobre el tema, aportando, en cambio, un cuerpo conceptual importante sobre la tipología de los retornados, su readaptación en las sociedades de origen y el impacto provocado en ellas por la vuelta de los emigrantes. Además, por lo común, 
las teorías enunciadas sobre el retorno migratorio han sido las mismas que se han utilizado para explicar los procesos emigratorios (Rivera, 2013). Si bien, varían de acuerdo al tipo de migración y la época en que se han ido sucediendo las principales oleadas de migrantes internacionales (Núñez, 2000; Egea, Nieto y Jiménez, 2002; Rodríguez y Egea, 2006).

Hasta mediados del siglo XX las teorías de la emigración se apoyaban básicamente en los principios de la Economía Política: racionalismo, individualismo y liberalismo (Massey et al., 2000). Es decir, se sustentaban en la idea de un hombre libre que escoge la alternativa que más le conviene desde un punto de vista de beneficio económico. Por tanto, en el caso de las migraciones, el balance en términos de costos y beneficios era el motor de las motivaciones individuales para emigrar y, en su caso retornar, si se habían cumplido las expectativas iniciales en la toma de decisión de emigrar.

Teorías como las del ciclo de vida que, en resumen, afirmaban que los migrantes escogen el tiempo de permanencia en el exterior en términos de su vida laboral, se aplicaron a la interpretación del retorno desde Alemania a países del sur de Europa y Turquía, a finales de los años 70 (Rodríguez y Egea, 2006). Otros autores hacen hincapié en la decisión del inmigrante de retornar solo cuando tiene los ahorros suficientes para invertir en un negocio en su propio país (Yang, 2004), dentro de corrientes teóricas más eclécticas que aúnan aspectos teóricos de las perspectivas economicistas y las del ciclo laboral. (Aboussi, 2012; Martín Ruiz, 2016).

La corriente neoclásica, basada en el presupuesto de la disparidad salarial como el motor que conduce a tomar la decisión de emigrar, interpreta el retorno como una consecuencia de la experiencia de fracaso del migrante (Todaro, 1969). Sus formulaciones teóricas tratan de explicar tanto la emigración como el retorno en términos de la imperfección de los mercados (Massey y Espinosa, 1997), teniendo en cuenta que, de forma general, el emigrante prefiere vivir en su propio país pero se ve impulsado a emigrar por los bajos salarios que existen en el mismo y solo decide retornar cuando ha acumulado el capital que considera necesario para satisfacer sus aspiraciones (Reyes, 1997), proceso que puede truncar una acusada crisis económica, por lo que el número de retornados desilusionados, según la categoría que establecen por ejemplo Herzog y Schlottmann (1982) aumenta drásticamente. Los trabajos más recientes en esta línea de interpretación consideran las migraciones como producto 
de los desequilibrios económicos mundiales y de la dependencia de parte de la población de los países más pobres de las condiciones que establecen los países más ricos (Constant y Massey, 2002). Así, la crisis que afecta a las naciones más desarrolladas y, en nuestro caso, a España impulsaría los retornos, pues, como ya señalaba hace casi cincuenta años Pierre George (1970), las características de la fuerza de trabajo procedentes de la inmigración vienen determinadas por el nivel de desarrollo y la estructura del mercado de trabajo de la nación receptora. A lo que se puede añadir, según las formulaciones teóricas de Portes y Bach (1985), que dado que los flujos migratorios tienden a satisfacer las necesidades de mano de obra del capital (King, 1986), la crisis económica hace que este les pueda considerar prescindibles y de ahí que se produzca un movimiento de retorno.

Por su parte, la perspectiva transnacional considera que la migración de retorno es parte del proceso migratorio, de carácter complejo y sistémico, que incluye relaciones económicas, sociales y culturales entre las sociedades de origen y las de destino, mediadas por un constante intercambio de recursos, dinero, bienes, ideas, información y valores (Levitt y Nyberg-Sorensen, 2004). Desde esta perspectiva, el abandono del lugar de destino puede no convertirse en retorno, sino llevar a un tercer lugar, incluso puede resultar una escala en el trayecto de la vida como inmigrante (Rivera, 2013). Así, el retorno aparece, desde las perspectivas transnacional y global de las migraciones, como la contraparte de los estudios sobre los procesos de integración/incorporación en las sociedades de destino, como parte de la experiencia de atravesar diversas fronteras y circular entre sociedades desiguales (Schramm, 2011; Glick-Schiller, 2013)

En el caso de España, ya Egea et al. (2002), señalaban que los estudios sobre retorno tendían a considerar, casi en exclusiva, la figura del emigrante retornado como equivalente al inmigrante fracasado, apreciación que se ha visto incrementada en el momento actual al ligar el retorno migratorio con las funestas consecuencias de la actual crisis económica entre los inmigrantes. Ciertamente el aumento del retorno migratorio coincide con la persistencia de la crisis, pero nos parece una simplificación excesiva considerar ésta la única causa que lleva a tomar la decisión del regreso al país de origen, el cual también se puede producir por otras razones, entre las que puede estar el cumplimento en España de las expectativas iniciales del emigrante. Por el contrario, el nivel de arraigo de las distintas nacionalidades de inmigrantes influye claramente en tasas 
menores de retorno entre aquéllos que llevan más tiempo en el lugar de destino (Izquierdo y Martínez-Buján, 2014).

Recientemente Jáuregui y Recaño (2014) han realizado un estudio que profundiza en las diferentes definiciones, tipologías y marcos teóricos aplicados en el tema del retorno migratorio, que sistematiza las principales aportaciones científicas al tema. Siguiendo la argumentación de estos autores se considera que uno de los objetivos clásicos dentro del estudio del retorno migratorio ha sido el de sus tipificaciones. Hace más de 40 años el sociólogo italiano Cerase (1974) realizó una tipificación de retornados teniendo en cuenta la relación con su integración sociolaboral en el lugar de acogida, en función tanto de su éxito profesional como de la movilidad social conseguida en comparación con su situación de partida. Así diferenciaba entre los retornados fracasados; los conservadores, que tras permanecer varios años y tener éxito han decidido ahorrar para retornar exitosos; los jubilados y los innovadores (que quieren volver para aplicar los conocimientos adquiridos en su lugar de acogida). Como señaló Núñez (2000) esta tipología ha sido muy discutida y muchos autores consideran que solo retornan los que no han experimentado una movilidad social muy alta, pues éstos se integran al máximo en el país receptor, ni tampoco los grandes fracasados que temen el rechazo en su lugar de origen, por lo que optan incluso por la marginalidad en el país de acogida.

Por otro lado, también hay que considerar una nueva situación que no se daba en anteriores etapas históricas y que se puede entender dentro de la teoría de la circularidad migratoria (LópezSala y Godenau, 2015) que explica cómo el retorno no tiene por qué transformarse en destino final (Herrera, Moncayo y Escobar, 2012), incluso no siempre el retorno es una etapa más en un proceso que lleva al migrante a un nuevo destino de emigración, sino que puede volver al mismo país del que partió a su lugar de origen, al reconsiderar la vuelta al país de inmigración como una opción mejor. Los movimientos incesantes entre distintos lugares forman parte de este concepto de circulación (Vega, Gómez Martín y Correa, 2016).

Pero volviendo a la idea clásica de regreso al lugar de origen, una de las clasificaciones más utilizadas es la que propuso Durand (2004), quien identifica cinco tipos de retorno migratorio: 1) el retorno decidido por el propio emigrante y definitivo tras una larga estancia en otro país en el que se han alcanzado las metas iníciales del proceso migratorio; 2) el retorno de trabajadores temporales, 
generalmente para tareas agrícolas; 3 ) el retorno transgeneracional: la vuelta de hijos o nietos de emigrantes; 4) el retorno forzoso, es el caso de los deportados; y 5) el retorno como fracaso del proceso migratorio cuando el inmigrante aprecia posibilidades de un retorno de éxito en el lugar de origen.

Dadas las características de la emigración internacional de los últimos años hacia España (Izquierdo, 1996) y otros países europeos se podrían añadir, a nuestro juicio, tres tipos de retorno más: 6) el retorno relacionado con "la crisis en el sistema de cuidados que se había establecido en el momento de la emigración” (Pérez Caramés, 2012: 78), especialmente cuando la mujer es la que emigra y deja a su familia a cargo de marido y/o padres (Vega y Martínez Buján, 2016); 7) el retorno incentivado y que se conoce como "retorno voluntario" (Iglesias, 2016); y 8) el retorno promovido por los gobiernos de países emisores para recuperar a aquellos compatriotas más cualificados intelectualmente (García Ballesteros y Jiménez Blasco, 2013; Mendoza, Staniscia y Ortiz, 2016).

En este trabajo analizaremos las fluctuaciones recientes en cuanto al retorno migratorio desde España a partir de las consideraciones teóricas planteadas, teniendo muy en cuenta que las tipologías de retornados deben ser continuamente revisadas y actualizadas a la luz de los cambios sociales y económicos que se producen, cada vez más rápidamente, como consecuencia de la nueva era de la información telemática y la globalización, fenómenos que están modificando, como no podía ser de otro modo, los procesos migratorios actuales.

\section{METODOLOGÍA Y FUENTES}

La metodología aplicada en este trabajo combina un análisis estadístico descriptivo de los flujos migratorios de retorno con un análisis cualitativo, basado en la observación participante y en entrevistas personales. Para su argumentación se ha consultado una amplia literatura científica sobre el tema del retorno migratorio. Se han manejado también documentos jurídicos, especialmente los relativos a los Programas de Retorno Voluntario del Ministerio de Empleo y Seguridad Social. En cuanto a las fuentes estadísticas destacamos la importancia de la Estadística de Variaciones Residenciales del Instituto Nacional de Estadística, así como otras 
fuentes de información de este organismo. También han sido muy útiles las estadísticas de los propios países de destino y las de algunos organismos como CEPAL (Comisión Económica para América Latina y el Caribe) y la OEI (Organización de Estados Iberoamericanos).

Asimismo, se han realizado entrevistas a inmigrantes que habían decidido la vuelta a su país y a familiares directos de retornados, ante la imposibilidad de viajar a múltiples destinos de retorno y encontrar allí testimonios de personas que hubieran regresado desde España. La información de las entrevistas, 35 en total, realizadas entre los años 2014 y 2016, resulta de gran eficacia para este propósito de investigación (Hernández Carrera, 2014). Fueron entrevistas no estructuradas para recoger los testimonios tal y como los entrevistados los recordaban (Fontana y Frey, 2005). También llevamos a cabo un total de 13 entrevistas semiestructuradas a trabajadores sociales, voluntarios de asociaciones e investigadores sociales que están en contacto con inmigrantes en situaciones de vulnerabilidad social. Estas últimas proporcionan una valiosa información, más estandarizada (Vallés, 2005), sobre las causas principales que conducen al retorno y que tipos de inmigrantes son los más proclives a éste.

En las entrevistas a inmigrantes se ha intentado que hubiera un cierto equilibrio por sexo, edad, ámbito laboral y país de procedencia. De algunas nacionalidades ha sido más difícil contar con testimonios, como por ejemplo de china, países indostánicos o países africanos, en parte por el problema del idioma y también, en algunos casos, por tener más recelos a la hora de ser entrevistados. En este sentido resultan más asequibles las personas procedentes de Latinoamérica por su afinidad cultural y lingüística y, dentro de los países del Este de Europa, se ha contado con más presencia de rumanos, como resultado del denominado efecto "bola de nieve", ya que los autores contaron en anteriores ocasiones con entrevistados rumanos, quienes nos pusieron en contacto con personas de esta nacionalidad que tenían familiares y amigos retornados. Para solventar el problema del sesgo por nacionalidades se ha recurrido a consultar las entrevistas realizadas por otros autores sobre colectivos menos numerosos en nuestro estudio: Gallego Losada (2012), en el caso de los marroquíes; Marcu (2012), para ucranianos, rusos, búlgaros y moldavos; Beltrán, Betrisey, López y Sáiz (2006), para asiáticos; y Petit (2002), en el caso concreto de los chinos. 


\section{LA EVOLUCIÓN RECIENTE DEL RETORNO MIGRATORIO DESDE ESPAÑA}

Según los datos del Instituto nacional de Estadística, la población residente en España pero nacida en otro país a 1 de julio de 2016 es de 6.123.769 personas, 636.011 menos que las que había a 1 de enero de 2012 (6.759.780), año para el que se registró la cifra máxima de residentes en España nacidos en otro país. A 1 de enero de 2017 la cifra, todavía provisional, es de 6.160.458 extranjeros empadronados en España, indicando un ligero aumento con respecto al 2016 (0,6\%).

En el Cuadro 1 se observa la evolución reciente de los saldos migratorios con el exterior en España. La evolución muestra una superación de los saldos negativos a partir de 2015 dentro del colectivo de extranjeros, si bien entre los españoles continúe el balance negativo, aunque ha disminuido claramente en el último año.

\section{CuAdro 1}

SALDOS MIGRATORIOS EXTERIORES POR NACIONALIDAD

\begin{tabular}{ccccccc}
\hline AÑO & TOTAL & $\%$ & ESPAÑOLES & $\%$ & EXTRANJEROS & $\%$ \\
\hline 2008 & 459.549 & 1,00 & Sin dato & - & Sin dato & - \\
\hline 2009 & 175.336 & 0,38 & Sin dato & - & Sin dato & - \\
2010 & 90.489 & 0,19 & Sin dato & - & Sin dato & - \\
\hline 2011 & 84.146 & 0,18 & Sin dato & - & Sin dato & - \\
2012 & -6.534 & -0.01 & -21.987 & $-0,05$ & 15.453 & 0,30 \\
2013 & -111.153 & $-0,24$ & -37.095 & $-0,09$ & -74.058 & $-1,52$ \\
\hline 2014 & -46.620 & $-0,10$ & -34.750 & $-0,08$ & -10.870 & $-0,24$ \\
\hline 2015 & 28.537 & 0,06 & -36.302 & $-0,09$ & 64.839 & 1,47 \\
\hline 2016 & 123.020 & 0,26 & -19.489 & $-0,05$ & 142.509 & 3,25 \\
\hline
\end{tabular}

Fuente: Estadística de variaciones residenciales. INE. Elaboración propia.

El cuadro 2 muestra que en 2016 todas las comunidades autónomas tuvieron saldos migratorios exteriores positivos, salvo la Comunidad Valenciana y Extremadura. Mientras que la situación en 2013 era la inversa, teniendo solo saldos positivos las dos comunidades insulares. 
CUAdRo 2

SALDOS MIGRATORIOS EXTERIORES DE EXTRANJEROS POR COMUNIDAD AUTÓNOMA

\begin{tabular}{lrrr}
\hline & \multicolumn{3}{c}{ SALDOS MIGRATORIO EXTERIOR } \\
& \multicolumn{1}{c}{ COMUNIDADES AUTÓNOMAS } & \multicolumn{1}{c}{2015} & \multicolumn{1}{c}{2016} \\
\hline ANDALUCÍA & -5.364 & 8.492 & 10.709 \\
\hline ARAGÓN & -1.208 & 1.371 & 3.607 \\
\hline ASTURIAS, PRINCIPADO DE & -219 & 561 & 1.447 \\
\hline BALEARS, ILLES & 414 & 6.905 & 11.065 \\
\hline CANARIAS & 8.342 & -2.970 & 17.984 \\
\hline CANTABRIA & -549 & 252 & 658 \\
\hline CASTILLA Y LEÓN & -2.190 & -320 & 1.797 \\
CASTILLA-LA MANCHA & -5.244 & 971 & 2.921 \\
\hline CATALUÑA & -13.736 & 28.253 & 49.719 \\
\hline COMUNITAD VALENCIANA & -18.025 & -7.357 & -3.398 \\
\hline EXTREMADURA & -79 & 1.115 & -641 \\
GALICIA & -588 & 2.449 & 5.064 \\
\hline MADRID, COMUNIDAD DE & -27.436 & 20.717 & 26.862 \\
\hline MURCIA, REGIÓN DE & -2.580 & -746 & 3.314 \\
\hline NAVARRA & -1.443 & 1.123 & 2.655 \\
\hline PAÍS VASCO & -1.856 & 3.525 & 7.463 \\
\hline RIOJA, LA & -1.665 & -49 & 925 \\
\hline CEUTA & -301 & 155 & 254 \\
\hline MELILLA & -331 & 392 & 104 \\
\hline TOTAL & -74.058 & 64.839 & 142.509 \\
\hline
\end{tabular}

Fuente: Estadística de variaciones residenciales. INE.

La figura 1 pone de relieve el drástico cambio que en solo dos años se ha producido en relación con los saldos migratorios exteriores de las diferentes comunidades autónomas españolas.

Respecto a la evolución reciente del número de bajas residenciales de los extranjeros empadronados en España con destino fuera de nuestras fronteras (Cuadro 3), se considera tanto a los que conservan su nacionalidad de origen como a los que han conseguido también la nacionalidad española.

El aumento de las bajas es notable entre los años 2008 y 2010, produciéndose algo más de 100.000 bajas en dos años. Posteriormente las cifras tienen una evolución errática hasta el año 2013, a partir del cual comienzan a descender en términos absolutos, lenta pero progresivamente, y en proporción lo hacen desde el año 2014. 
FIgURA 1

SALDOS MIGRATORIOS EXTERIORES EN ESPAÑA 2013 Y 2015

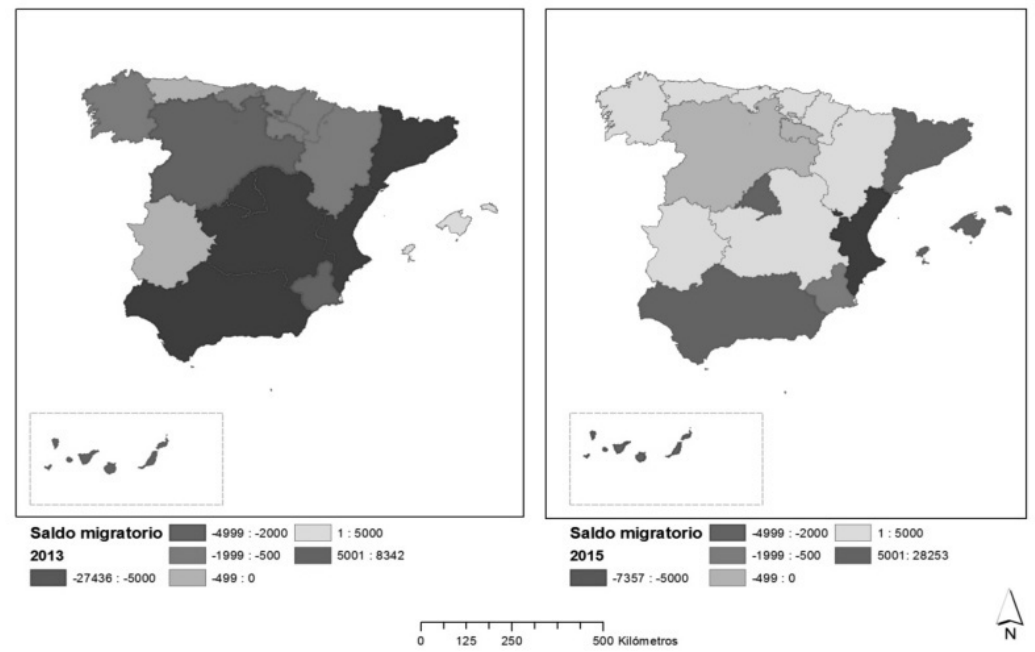

Fuente: Estadística de variaciones residenciales. INE. Elaboración propia.

Cuadro 3

EVOLUCIÓN RECIENTE DE LAS BAJAS RESIDENCIALES DE EXTRANJEROS

\begin{tabular}{cccc}
\hline AÑOS & $\begin{array}{c}\text { BAJAS RESIDENCIALES } \\
\text { DE EXTRANJEROS }\end{array}$ & $\begin{array}{c}\text { NACIDOS EN EL EXTRANJERO } \\
\text { RESIDENTES EN ESPAÑA }\end{array}$ & PORCENTAJE \\
\hline 2008 & 233.407 & 6.044 .528 & 3,86 \\
2009 & 289.414 & 6.466 .278 & 4,46 \\
2010 & 334.743 & 6.604 .181 & 5,07 \\
2011 & 319.871 & 6.677 .839 & 4,79 \\
2012 & 325.383 & 6.759 .780 & 4,81 \\
2013 & 389.875 & 6.640 .536 & 5,87 \\
2014 & 378.764 & 6.283 .712 & 6,03 \\
2015 & 352.269 & 6.162 .932 & 5,72 \\
2016 & 340.046 & 6.123 .769 & 5,55 \\
\hline
\end{tabular}

Fuente: Estadística de variaciones residenciales. INE. Elaboración propia. 
El colectivo de extranjeros más numeroso en cuanto al número de bajas residenciales durante el período 2008-2016, sin contar la Unión Europea, corresponde a los oriundos de países latinoamericanos, pero en 2016 solo Ecuador, mantiene un saldo migratorio negativo (cuadro 4), contrastando con la situación del año 2012 cuando eran nueve los países latinoamericanos con saldos negativos (Argentina, Bolivia, Brasil, Colombia, Chile, Ecuador, Paraguay, Perú y Uruguay).

CUADRO 4

PAÍSES CON SALDOS MIGRATORIOS NEGATIVOS EN 2016

\begin{tabular}{lccc}
\hline $\begin{array}{c}\text { PAIS DE } \\
\text { NACIONALIDAD }\end{array}$ & RESIDENTES EN ESPAÑA & $\begin{array}{c}\text { SALDOS } \\
\text { MIGRATORIOS }\end{array}$ & PORCENTAJE \\
\hline RUMANÍA & 638.018 & -12.237 & $-1,92$ \\
\hline ECUADOR & 411.997 & -1.118 & $-0,27$ \\
BULGARIA & 124.342 & -2.990 & $-2,40$ \\
\hline PORTUGAL & 110.549 & -1.650 & $-1,49$ \\
POLONIA & 63.274 & -1.720 & $-2,72$ \\
\hline
\end{tabular}

Fuente: Estadística de variaciones residenciales. INE. Elaboración propia.

Actualmente, como se observa en el cuadro 4, el país que arroja un saldo negativo más elevado es Rumanía. Sin embargo, en términos relativos, es Polonia el país con mayor tasa de retorno, considerando solo los que tienen saldo migratorio negativo. Pero en el cuadro 5 incluimos aquellos países con mayor número de retornados en 2016, sin tener en cuenta el signo del saldo migratorio. De este modo queda patente la primacía de Rumanía en el número de bajas residenciales, pero muestra también una cifra importante Marruecos y a más distancia Colombia, cuyo porcentaje de bajas es similar al de Ecuador, país latinoamericano con más inmigrantes en España, seguido, precisamente, de Colombia. 
Cuadro 5

PAÍSES DE NACIMIENTO CON MÁS DE 10.000 BAJAS RESIDENCIALES EN 2016

\begin{tabular}{lcc}
\hline \multicolumn{1}{c}{ PAÍS DE NACIMIENTO } & BAJAS RESIDENCIALES & $\begin{array}{c}\text { PORCENTAJE } \\
\text { SOBRE EL TOTAL DE RESIDENTES }\end{array}$ \\
\hline RUMANÍA & 52.215 & 8,44 \\
MARRUECOS & 29.786 & 4,27 \\
ECUADOR & 15.718 & 3,86 \\
COLOMBIA & 13.751 & 3,89 \\
BULGARIA & 10.254 & 8,48 \\
\hline
\end{tabular}

Fuente: Estadística de variaciones residenciales. INE. Elaboración propia.

\section{MOTIVOS POTENCIALES PARA EL RETORNO MIGRATORIO}

Cuando comenzamos a trabajar sobre la emigración de retorno en España, suponíamos que la crisis económica ligada al fuerte aumento del paro sería la causa fundamental para decidir el regreso al país de origen, o en todo caso, el inicio de una nueva vida en otro destino (Medinaet al. 2010). Sin embargo, en nuestra primera investigación sobre retorno migratorio, las principales razones que indicaban los entrevistados eran de índole familiar y/o personal. Así, los inmigrantes entrevistados entonces referían motivos relacionados con los hijos principalmente. El bienestar de los hijos es un factor muy común en la decisión de emigrar o retornar (Gregorio, 2002; Parella, 2003; Recaño y Jaúregi (2014). En general, las mujeres entrevistadas que vinieron a España dejando a sus hijos en los lugares de origen nos comentaron, a menudo, que tomarían la decisión de regresar a su país, si percibían que los cuidadores de sus hijos no conseguían controlar bien determinadas situaciones; en esta misma línea encontramos referencias de otros autores (Martínez-Buján, 2015). Un motivo alegado, sobre todo por las mujeres, son los problemas con los hijos cuando llegan a edades adolescentes y jóvenes. También se señala en algunas entrevistas el cambio en la situación de salud de los padres de los inmigrantes, pues de haber sido los cuidadores 
de sus hijos pasaban a ser población dependiente al llegar a edades avanzadas (García Ballesteros et al., 2014). En bastantes casos observamos que se estaba produciendo un fenómeno inverso al de la reagrupación familiar, es decir, una ruptura de las familias al regresar algún miembro. Esta situación se da más entre la población de origen latinoamericano donde a menudo la mujer ha sido la pionera en el proceso migratorio. En cambio desde lugares de origen, como Marruecos con una inmigración más masculinizada las encuestas indican que un gran número de marroquíes está en contra del retorno. En ese sentido, las bajas cifras de solicitantes marroquíes de los programas de retorno voluntario (Gallego, 2012).

En las citadas entrevistas las razones económicas se señalaban en un segundo puesto como la causa principal del retorno, pero la crisis económica estaba en la base de muchos proyectos de regreso al país de origen, aunque tuvieran un detonante familiar. La causa principal dentro de los motivos de índole económica era la falta de empleo, sobre todo, si esta situación la padecían varios miembros de una misma familia. El fracaso en las empresas o negocios montados por inmigrantes en España es un motivo muy minoritario para decidir un regreso al país de origen, al menos así se desprende de las entrevistas realizadas. Generalmente, los negocios de inmigrantes se han establecido con poca inversión, son muy versátiles, han soportado mejor la crisis que otros nichos laborales típicos para inmigrantes, especialmente el de la construcción (García Ballesteros et al., 2014, p. 120; Cebrián, Jiménez Blasco y Resino, 2016).

En cambio, en las entrevistas más recientes, realizadas para esta investigación, la causa más alegada como motor del retorno al país de origen es la económica, principalmente el desempleo (Colectivo IOÉ, 2011) y no se señalan tanto las razones familiares como en las entrevistas que se hicieron en los años 2012 y 2013 (García Ballesteros et al., 2014). En este sentido, hay que destacar que el paro entre los inmigrantes es particularmente elevado. Según la Encuesta de Población Activa (EPA) del primer trimestre de 2017, la tasa de paro de la población extranjera es de 25,46, mientras que para la población española es del 17,85 (Instituto Nacional de Estadística, INE, 2017).

Los inmigrantes del Este de Europa señalan principalmente la falta de trabajo como causa del retorno, especialmente las 
mujeres. En cambio los varones alegan más el deseo de retorno al lugar de origen por haber cumplido en España sus expectativas económicas.

Si no hay trabajo en España es mejor volver a Rumanía porque la familia te puede ayudar. (Mujer rumana, 45 años, trabajadora del servicio doméstico, hermana de retornada)

Mi padre decidió volver porque tenía ahorros que le permiten vivir mejor allí que aquí. (Varón eslovaco, 28 años, emprendedor, hijo de retornado)

En el caso de los latinoamericanos, las razones que les llevan al regreso a sus países son principalmente la falta de trabajo, los incentivos que pueden conseguir si se acogen a planes de retorno voluntario y las razones de índole familiar (cuadro 6), estas últimas afectan más a las mujeres que a los hombres, pues muchas relatan problemas de los hijos que han dejado en sus países y también situaciones de dependencia de los abuelos que, precisamente, habían sido los cuidadores de los hijos mientras eran pequeños y sus padres decidieron emigrar.

Al morir mi madre, mi hermana decidió volver porque mi padre era muy mayor para estar solo. (Mujer hondureña, 45 años, auxiliar de geriatría, hermana de retornada)

En la actualidad se están produciendo dos procesos en relación con las migraciones y concretamente con el tema del retorno, inéditos en épocas pasadas. El primero de ellos se refiere a la existencia de Programas de Retorno Voluntario Asistido, adoptados por un gran número de países con fuertes tasas de inmigración, que pretenden ayudar a volver a sus países de origen a aquellos inmigrantes en situaciones precarias y que suelen constituir una pesada carga socioeconómica para los servicios sociales de los países de destino. El segundo de los procesos se trata de planes provenientes de algunos gobiernos de países fuertemente emisores que intentan atraer de nuevo a sus connacionales, considerándolos como un capital humano cuya emigración beneficia a los países ricos y perjudica el crecimiento y desarrollo de los países de emigración (Cassarino, 2013). Por lo tanto, no se trata de procesos complementarios, sino que ambos desean la permanencia en sus países de los migrantes más productivos y la expulsión de aquellos que generan más gasto social. 
En España se contemplan tres posibles vías por las que los nacionales de terceros países pueden acogerse a los Programas de Retorno Voluntario Asistido: encontrarse en situación de vulnerabilidad social, tener intención de reintegrarse socioeconómicamente en su país de origen y percibir por anticipado la prestación por desempleo. Los oriundos de los países latinoamericanos son los principales solicitantes de retorno voluntario (Cuadro 6). Los que se acogen a estos planes deben aceptar el compromiso de no retornar a España en el plazo de tres años a partir de la fecha del retorno. En relación con esto último, en algunas entrevistas nos afirman que conocen casos de inmigrantes que, una vez pasados los tres años de permanencia en su país, están volviendo de nuevo al nuestro. En la mayoría de los casos detectados observamos que se trata siempre de retornados que dejaron en España parte de sus familias, amigos y contactos de su etapa anterior al retorno. Quizás este sea un motivo más que explique la reactivación de las llegadas de inmigrantes a España, según los últimos datos ofrecidos por el INE (Cuadro 1)

\section{CuAdro 6}

PROGRAMA DE RETORNO VOLUNTARIO DE ATENCIÓN SOCIAL(2009-2014)

\begin{tabular}{lcc}
\hline \multicolumn{1}{c}{ PAÍS } & NÚMERO & PORCENTAJE CON RESPECTOA \\
\multicolumn{1}{c}{ DE NACIONALIDAD } & DE RETORNADOS & LOS RESIDENTES EN ESPAÑA EN 2009 \\
\hline ARGENTINA & 1.925 & 1,40 \\
\hline BOLIVIA & 3.250 & 1,48 \\
BRASIL & 1.913 & 1,78 \\
\hline CHILE & 969 & 2,16 \\
COLOMBIA & 847 & 0,28 \\
\hline ECUADOR & 1.653 & 0,39 \\
HONDURAS & 788 & 3,22 \\
\hline PARAGUAY & 1.157 & 1,47 \\
PERÚ & 389 & 0,28 \\
\hline URUGUAY & 873 & 1,79 \\
\hline
\end{tabular}

Fuente: Ministerio de Empleo y Seguridad Social. Dirección General de Migraciones.

Elaboración propia. 
Así, por ejemplo, el actual gobierno de Ecuador ha puesto en marcha una serie de programas para apoyar el retorno de sus emigrantes mediante incentivos fiscales y de captación especialmente de profesionales del ámbito de la innovación y el desarrollo. Esto puede explicar el elevado porcentaje de deseo de abandonar España (70\%) que, según una encuesta elaborada por la Secretaría Nacional del Migrante de Ecuador, mostraban los ecuatorianos residentes en nuestro país (Iglesias, 2016).

\section{EL ARRAIGO EN ESPAÑA COMO FRENO DEL RETORNO}

Los factores de arraigo actúan contra la toma de decisión del retorno. Entre los más importantes están la reagrupación familiar, la existencia de lazos familiares con españoles (especialmente nupcialidad), la compra de vivienda en España y la obtención de la nacionalidad española. Estos motivos han sido destacados en las entrevistas realizadas, tanto a mujeres como hombres, y también hay un cierto grado de consenso entre distintas nacionalidades.

Cuando se ha producido una inmigración casi total de los miembros de una misma familia, éstos buscan distintas salidas laborales o incluso aceptan una cierta movilidad, pero sin salir de España (Gil, Bayona y Vono, 2012; Izquierdo y Martínez-Buján, 2014). Así tenemos algunos testimonios:

Aunque me quedé sin trabajo, permanecí en España aunque tuve que irme de Madrid a Zaragoza porque allí tenía hermanos... En Bogotá ya casi no queda nadie de la familia. (Varón Colombiano, 40 años, parado)

La obtención de la nacionalidad española podría considerarse $a$ priori como un motivo de arraigo $\mathrm{y}$, por tanto, de desaliento a la hora de decidir la vuelta al país de origen (Gil Rodríguez, 2000; Sampedro y Camarero, 2016). Sin embargo, algunos nacionalizados se encuentran más dispuestos al retorno, precisamente porque al tener las dos nacionalidades consideran que dejan una puerta abierta en España para un futuro regreso, siempre que las condiciones sociolaborales sean más atractivas que actualmente.

Vuelvo a Marruecos... si no me adapto de nuevo, me vuelvo a España porque tengo la nacionalidad. (Varón marroquí, 50 años, obrero) 
La adquisición de la nacionalidad española se convierte en una ventaja para la reemigración pues facilita el traslado a otros países de la Unión Europea y tampoco supone un factor de retención para los que deciden retornar a su país de nacimiento, como se constató en anteriores investigaciones (García Ballesteros et al., 2014).

La nupcialidad con autóctonos constituye un factor importante de no retorno (Alba, 2001), pues los lazos familiares con la pareja y la familia de ésta implican, lógicamente, un fuerte arraigo en España y en momentos de penuria suponen un respaldo económico, personal y social normalmente efectivo. La nupcialidad entre españoles y extranjeros ha sido relativamente alta si bien va en descenso en los últimos años. Así en el 11,94\% de los matrimonios celebrados en 2016 uno de ellos era extranjero. Este porcentaje fue inferior al $16,4 \%$ registrado en 2014 y al 12,98\% de 2015.

Por el contrario, las separaciones y divorcios motivan muchas veces la vuelta del miembro no español de la pareja a sus orígenes, sumándose dificultades personales y familiares a problemas económicos y estructurales (Blanco, 2000).

Al separarme de mi segundo marido que era español decidí volverme a mi país con mis hijas. (Mujer dominicana, 33 años, camarera, retornada)

Uno de los factores de permanencia es el tiempo de residencia en España. Los inmigrantes que llegaron en la década de los 90 parecen ser menos favorables a la idea del retorno, pues su integración en la sociedad receptora es mayor y suelen contar con una red social de mutua ayuda que les permite sortear mejor los problemas derivados de la crisis económica, de forma similar a lo que ocurre con los autóctonos. No obstante, los programas de retorno voluntario han incentivado la vuelta a los países de origen a inmigrantes con derecho a paro y una relativa antigüedad en España, así según los datos del Censo del Ecuador de 2010 los emigrantes retornados ecuatorianos tenían una estructura poblacional más envejecida y un ligero predominio masculino (Recaño y Jaúregui, 2014).

Mi marido volvió porque le interesó cobrar el paro en Ecuador y permanecer allí tres años, ya que en España los trabajos que le salían estaban muy mal pagados. (Mujer ecuatoriana, 38 años, empleada del servicio doméstico, esposa, hija y madre de retornados) 
Si bien, en general, los inmigrantes más recientes y, sobre todo, los irregulares se encuentran mucho más desprotegidos socialmente y son más proclives a tomar una decisión de abandono de España, bien para volver a su país o bien para ir a otro destino. Así, por ejemplo, según las entrevistas realizadas se están volviendo más aquéllos que vinieron a España en la primera década del siglo XXI que en las dos últimas del siglo XX (García Ballesteros et al., 2014).

Mi hijo pertenece al ejército español. Yo ya me siento de aquí, me vine hace casi treinta años. (Mujer paquistaní, 54 años, comercio)

La compra de vivienda en España también actúa como una fuerza de retención para los inmigrantes. Por el contrario, la situación de alquiler propicia más el retorno, siempre que se den otras condiciones económicas, familiares y sociales que actúen como factores de expulsión. El testimonio de varios entrevistados nos indica esta situación, por ejemplo:

Mis padres vivían de alquiler en Madrid y sin trabajo era imposible pagarlo así que se volvieron a Lima. (Mujer peruana, 35 años, trabajadora del servicio doméstico, esposa e hija de retornados)

Por otro lado, las situaciones de desahucio, impago de hipotecas, etc. provocan a menudo la paralización de un posible retorno, salvo que se pacte con el banco una dación en pago, liberándolos de deudas hipotecarias, lo cual parece que propicia la vuelta a su lugar de origen $u$ otro proyecto migratorio en otro país, por lo general en la Europa Comunitaria.

Finalmente, la persistencia en la mala percepción de la economía de los países de origen anima a desistir del retorno migratorio, pues se considera que la situación en ellos podría ser aún peor que en España.

En España vivo mejor que en África aunque me quedara en la calle. (Varón de Nigeria, 45 años, portero de un inmueble)

Asimismo la percepción de que pese a la situación económica las prestaciones sociales en materia de educación, sanidad y desempleo son mejores que en sus países de origen, también actúa como factor de permanencia. 
A pesar de estar en paro no me vuelvo a mi país porque mis hijos tienen más posibilidades si estudian en España que en mi país. (Varón rumano, 37 años, trabajador de la construcción en paro, hermano de retornado)

En general, de las entrevistas realizadas se desprende un ligero predominio de los varones sobre las mujeres en los retornos. Lo cual es confirmado por la Encuesta de Variaciones Residenciales del INE, en la que se constata que el número de bajas residenciales de los varones extranjeros en 2016 fue un poco más del 10\% superior al de las mujeres extranjeras. El trabajo de Recaño y Jaúregui (2014) sobre el retorno a Latinoamérica también confirma esta tendencia. Dichos autores señalan que la mujer latinoamericana ha ocupado un papel destacado en el sector de los servicios, con menores tasas de paro durante la crisis, pero que "los inmigrantes masculinos se han vinculado más a sectores de la economía de baja cualificación - como la agricultura y la construcción-, muy castigados por la crisis, abocados a una mayor propensión a la emigración exterior". Esto mismo se ha observado entre los entrevistados de los países del Este, pero no tanto entre los varones procedentes de China y países indostánicos, quienes se han insertado fundamentalmente en las actividades comerciales y la hostelería, afectadas por la crisis, pero que se han mantenido adaptándose a la nueva situación en un tiempo récord (Cebrián et al., 2016).

\section{CONSIDERACIONES FINALES A MODO DE CONCLUSIÓN}

En la toma de decisión del retorno migratorio sobresalen tres factores determinantes: la situación laboral, familiar y legal en el país de acogida. Según sean las condiciones del inmigrante en estos tres ámbitos aumentan o, por el contrario, disminuyen las posibilidades de retorno.

Indudablemente la modificación de las condiciones económicas que motivaron la emigración incide de forma clara en la decisión de retornar de forma voluntaria. El paro unido a las escasas perspectivas de reinserción en el mercado laboral es un hecho fundamental. Sin embargo, si no se percibe que se ha modificado positivamente la situación del lugar de partida hay reticencias a la hora de tomar la decisión de retornar, como ponen de manifiesto las entrevistas 
realizadas por los autores de este trabajo y las que se han llevado a cabo dentro de otros estudios de retorno migratorio (Mahía, 2014). Hay que tener en cuenta que las migraciones son un hecho estructural y por tanto las fluctuaciones en la situación económica de los países implicados van a determinar la dirección de los flujos (López de Lera y Pérez Caramés, 2015).

Actualmente en España, muchos inmigrantes antes de retornar intentan explorar las opciones de otros países de la Unión Europea, aprovechando las redes sociales con las que cuentan en ellos y las posibilidades de movilidad que les ofrece el estar ya dentro del espacio europeo y el contar en algunos casos con la nacionalidad española. Incluso antes de tomar la decisión de retornar se prefiere explorar todas las posibilidades que ofrece la situación del paro e incluso el trabajo precario y sumergido, en especial si la estancia en España es legal y especialmente si se cuenta con la nacionalidad española. El retorno desilusionado, sin cumplir el mínimo de los objetivos del proyecto migratorio, es una opción que se retrasa al máximo.

Sin duda las cifras de regreso de inmigrantes en España a sus países de origen se fue incrementando significativamente desde el comienzo de la crisis económica, lo cual apunta a que en la base de la decisión de la vuelta al lugar de nacimiento están los motivos económicos, principalmente el desempleo. No obstante, a tenor de las contestaciones que nos dan las personas entrevistadas, parece que, a menudo, el detonante del retorno migratorio está en la existencia de problemas familiares, comúnmente relacionados con el cuidado de los hijos o de los padres que estuvieron atendiendo a éstos, estas razones de índole familiar las refieren sobre todo los inmigrantes procedentes del Este de Europa y los latinoamericanos; asiáticos y africanos las consideran en mucha menor medida.

El trabajo de observación, junto con las entrevistas llevadas a cabo, nos han permitido distinguir varios tipos de retornados. El primero de ellos responde a aquellos inmigrantes que se han integrado muy poco en la sociedad receptora, que no han hecho reagrupamiento familiar y finalmente retornan, bien beneficiándose de los programas de retorno voluntario, o bien sin ellos, con un evidente fracaso en su proyecto migratorio. Un segundo grupo está formado por personas que han obtenido un dinero suficiente en España y desean volver a sus países porque tienen hijos en sus lugares de origen o ascendientes enfermos y/o dependientes, y consideran necesaria 
su vuelta para atenderlos. Finalmente, encontramos retornos de personas jóvenes que, o bien vinieron siendo niños a nuestro país o incluso nacieron en España, pero que no encuentran trabajo y tampoco completan una formación académica y/o profesional, de modo que consideran una vuelta a sus países de origen como una oportunidad de integrarse y desenvolverse mejor allí desde un punto de vista laboral, social y familiar.

De acuerdo con nuestras indagaciones, el retorno migratorio no constituye hoy en día en España un flujo demográfico masivo, incluso tampoco lo fue durante los años más duros de la crisis, si lo consideramos en términos relativos. Si bien, en los medios de comunicación tuvo un gran eco y se valoró de muy distinta forma por la población autóctona, para algunos se percibió como un pésimo indicador de la economía del país, mientras que otros vieron en este supuesto retorno masivo de inmigrantes una posible solución para el elevado desempleo, consecuencia más dramática de la crisis en España. Por tanto, no consideramos, por el momento, que España se haya convertido actualmente en un país de emigración. El saldo migratorio con el extranjero, según los datos del INE, ha pasado de ser positivo en 2011 a negativo entre 2012 y 2014, volviendo a ser positivo en 2015 y 2016. No obstante, estas cifras pueden sufrir altibajos, dependiendo de muchos factores coyunturales tanto de nuestro país, como de los países de origen de los que retornan.

Es necesario, en posteriores trabajos de investigación, ahondar más en los factores que desencadenan el deseo de regreso al lugar de origen y en las diferencias según distintas nacionalidades.

La existencia de mayores vínculos con los lugares de partida como motor del retorno es también un interesante campo de estudio, debiéndose profundizar en su impacto diferencial en distintas generaciones de emigrantes. También debemos analizar con mayor detalle el impacto de las políticas que alientan los retornos, tanto las del país receptor, como las de los países emisores de emigrantes que quieren ahora la vuelta de sus compatriotas y, en especial, de los más cualificados sin olvidar que una importante corriente de retorno migratorio tendrá indudables consecuencias para el país receptor en su demografía, mercado laboral, y, en general, en su economía; así como también producirá impactos en las sociedades de origen de dichos emigrantes

Ir, volver o cambiar de lugar de trabajo y vida en la era de la globalización debería ser un proceso más abierto que lo que los 
estudios realizados al respecto nos demuestran. Obviamente las personas no pueden traspasar las fronteras tan fácilmente como lo hacen la información y el dinero. Las cuestiones que surgen en el estudio de las migraciones humanas son mucho más complejas que las relativas a la circulación de bienes y capitales y el caso de los retornos es un buen ejemplo.

\section{LISTA DE REFERENCIAS}

Aвoussi, M. (Coord.) (2012): El codesarrollo a debate. Granada: Comares.

AlBA, F. (2001): Las migraciones internacionales. México: Conaculta.

Arango, J. (1985): Las Leyes de las Migraciones de E. G. Ravenstein, cien años después. Revista Española de Investigaciones Sociológicas, 32, pp. 7-26.

Beltrán, J., Betrisey, D., López, A. M., Sáiz, A. (2005): El estado de la cuestión de la investigación sobre las comunidades asiáticas en España. En SAN Ginés Aguilar P. (ed.). La investigación sobre Asia-Pacífico en España. Granada, Universidad de Granada.

BANCO DE EsPaÑa (2012): Balanza de pagos y posición de inversión internacional en España. Madrid: Eurosistema.

Blanco, C. (2000): Las migraciones contemporáneas, Madrid: Alianza Editorial.

CASSARINO, J. P. (2013): Teorizando sobre la migración de retorno: un abordaje conceptual revisitado sobre migrantes de retorno. Revista Interdisciplinaria de Movilidad Humana, Brasilia, 21(4), pp. 21-54.

Cebrí́n, J. A., Bodega, M. I., Martín-Lou, M. A. y Guajardo, F. (2010): La crisis económica internacional y sus repercusiones en España y en su población inmigrante. Estudios Geográficos, 71, 268, pp. 67-101.

Cebrián de Miguel, J. A., Jiménez Blasco, B. C. y Resino, R. M. (2016): Inmigrantes emprendedores durante la crisis económica. Estudio de casos en la ciudad de Madrid. Revista Migraciones, 40, pp. 63-92.

Centro de Estudios del Cambio Social (2011): Informe España 2011. Una interpretación de su realidad social, Madrid: Fundación Encuentro.

CERASE, F. P. (1974): Migration and social change: expectations and reality. A case study of return migration from the United States to Southern Italy. International Migration Review, 8, pp. 245-262.

Colectivo IOÉ (2011): Notas sobre los efectos socioeconómicos de la crisis para la población inmigrada. Papeles de relaciones ecosociales y cambio global, 113, pp. 85-95

Comisión Económica para América Latina y el Caribe (2016): Consultado el 15 de diciembre de 2016 (http://www.cepal.org/es/datos-y-estadisticas) 
Constant, A. and Massey, D. (2002): Return Migration by German Guestworkers: Neoclassical Versus New Economic Theories. International Migration, 40 , pp. 5-39.

Durand, J. (2004): Ensayo teórico sobre la migración de retorno. El principio del rendimiento decreciente. Cuadernos Geográficos, 35, pp. 103-116.

DuRAND, J. (2006): Los inmigrantes también emigran: la migración de retorno como corolario del proceso. REMHU - Revista Interdisciplinar da Mobilidade Humana, Ano XIV, 26 y 27.

Egea, C., Nieto, J. A. y Jiménez, F. (2002): El estudio del retorno. Aproximación bibliográfica. Migraciones y exilios, 3, pp. 141-168.

Fondo Monetario Internacional (2013): Perspectivas de la economía mundial: transiciones y tensiones. Washington: FMI/Infolatam.

Fontana, A. y Frey, J. (2005): The Interview, from neutral stance to political involvement. In N. K. Denzin \& y S., Lincoln (Comp). The Sage Handbook of Qualitative Research (695-727). London, UK: Sage.

Fuente Rodríguez, Y. DE La (2003): La emigración de retorno. Un fenómeno de actualidad. Alternativas. Cuadernos de Trabajo Social, 11, pp. 149-166.

Gallego Losada, R. (2012): La inmigración marroquí y su retorno en el contexto de la crisis económica, Revista de Derecho Migratorio y Extranjería, 29, pp. 307-338.

García Ballesteros, A., Jiménez Blasco, B. C., Mayoral, M. y Viñas, G. (2012): La actividad empresarial de los inmigrantes emprendedores en la Comunidad de Madrid. En LóPez, F.; García, F. y Mourad (Coord.) Empresariado inmigrante. Instituciones y desarrollo. Granada: Comares.

García Ballesteros, A. y Jiménez Blasco, B. C. (2013): Migration. Spain’s Reverse Flows. American Quaterly, Winter, pp.133-135.

García Ballesteros, A., Jiménez Blasco, B. C. y Mayoral, M. (2014): Emigración de retorno y crisis en España. Scripta Nova, Vol. XVIII, 491.

García Ballesteros, A., Redondo González, A. y Jiménez Blasco, B. C. (2009): La inmigración latinoamericana en España en el siglo XXI. Investigaciones Geográficas, 70, pp. 55-70.

George, P. (1970): Types of migration of the population according to the professional and social composition of migrants. In C. J. JANSEN (Ed.). Readings in the sociology of migration. Oxford.

GIL Rodríguez, J. (2000): Conservación y pérdida de la nacionalidad española (en el supuesto de emigración). La extranjería privilegiada y el tránsito de la condición de extranjero a la de nacional (en la perspectiva de la inmigración). La recuperación de la nacionalidad española (pensando en el retorno). Revista da Escola Galega de Administración Pública, 24, pp. 51-74.

GiL, F., Bayona J. y Vono, D. (2012): Las migraciones internas de los latinoamericanos en España: del boom a la crisis económica. Papeles de Población, 71, enero-marzo, pp. 1-41.

Glick-Schiller, N. (2013): Transnational Social Fields and Imperialism: Bringing a theory of power to the transnational studies. Rev. Interdiscipl. Mobil. Hum., Brasília, XXI, 41, pp. 55-76. 
Gmelch, G. (1980): Return Migration. Annual Review of Anthropology, 9, pp. 135-159.

Gregorio, C. (2002): La movilidad transnacional de las mujeres: entre la negociación y el control de sus ausencias y presencias, Gregorio C. y Agrela, B. (eds.) Mujeres de un solo mundo: globalización y multiculturalismo, Granada: Universidad de Granada.

Hernández Carrera, M. (2014): La investigación cualitativa a través de entrevistas: su análisis mediante la teoría fundamentada. Cuestiones Pedagógicas, 23, pp. 187-210.

Herrera, G., Moncayo, M., Escobar, A. (2012): Perfil migratorio del Ecuador 2011. Ecuador, Organización Internacional para las Migraciones (OIM), Ecuador.

Herzog, H. y Schlottmann, A. M. (1982): Moving Bach vs. Moving On: The Concept of Home in the Decision to Remigrate. Journal of Regional Science, 22, pp. 73-82.

Iglesias SÁNCHEZ, S. (2012): El retorno voluntario en España: análisis desde la perspectiva de la migración circular y del derecho de la Unión. Revista de Derecho Migratorio y Extranjería, 29, pp. 243-262.

Iglesias, J. (2016): Stay or Go? Ecuadorian Immigrants in Spain in Times of Crisis: Ecuadorian Immigrants in Spain. Bulletin of Latin American Research. Early View. October 2016. DOI: 10.1111/blar.12560

Instituto Nacional de Estadistica. (2017): Encuesta de Población Activa (EPA). Primer Trimestre 2017. Madrid. Instituto Nacional de Estadística.

Izouierdo, A. (1996): La inmigración inesperada. Barcelona: Trotta.

Izquierdo, A. y Martínez-Buján, R. (2014): From Favourites to 'With no Return': Permanence and Mobility of Latin American Immigration in Spain during the 21st Century. Canadian Ethnic Studies, 46 (3), pp. 103-130.

JÁuREgui, J. A. y RECAÑo, J. (2014): Una aproximación a las definiciones, tipologías y marcos teóricos de la migración de retorno. Biblio $3 W$ GeoCrítica. Vol. XIX, n 1084.

Jiménez Blasco, B. C. y Redondo González, A. (2007): Mujeres inmigrantes en la ciudad de Madrid: algunos aspectos sobre su inserción laboral, conciliación familiar y salud. Anales de Geografía de la Universidad Complutense, 27 (2), pp. 60-76.

Jiménez Blasco, B. C., García Ballesteros, A. y Redondo González, A. (2012): La inmigración latinoamericana en España en el siglo XXI. Editorial Académica Española.

Jiménez Blasco, B. C.; Mayoral, M. y Martín Jiménez, A. (2008): Los negocios de los inmigrantes latinoamericanos en Madrid. En F. J. Antón Burgos. y S. Sánchez Moral (Eds.). Comercio, servicios y transporte. Patrones de una sociedad avanzada. Grupo de Geografía de los Servicios. Asociación de Geógrafos Españoles, pp. 215-226.

Jiménez Blasco, B. C. y Mayoral, M. (2013): España, ¿un país de ida y vuelta?. En III Jornadas de Investigación del Departamento de Geografía Humana 
de la Universidad Complutense de Madrid. Madrid: Departamento de Geografía Humana de la UCM.

KING, R. (1986): Return migration and regional economic problems, London, Croom Helm.

Levitt, P. y Nyberg-Sorensen, N. (2004): The Transnational Turn in Migration Studies. Global Migration Perspectives, $\mathrm{n}^{\circ} .6$.

López de Lera, D. y Pérez Camarés, A. (2015): La decisión de retornar en tiempos de crisis. Una perspectiva comparada de los migrantes ecuatorianos y rumanos en España. Migraciones, 37, pp. 171-194.

López-Sala, A. y Godenau, D. (2015): En torno a la Circularidad Migratoria: Aproximaciones conceptuales, Dimensiones teóricas y Práctica Política. Migraciones, 38, pp. 9-34.

Maнía, R. (2014): Reflexión del fenómeno del Retorno desde Europa: análisis de los flujos migratorios y el retorno; previsiones a largo plazo. En Retorno Voluntario: Desde Europa hacia América Latina. OEI.

MARcu, S. (2012): De Rusia a España: movimientos migratorios transfronterizos en la Eurasia del siglo XXI. Madrid: UNED.

Martín Ruiz, J. F. y Arranz Lozano, M. (2009): Los factores del desarrollo socioeconómico y territorial de Marruecos: la aportación de las remesas de sus emigrantes. Anales de Geografía de la Universidad Complutense, 29 (2), pp. 9-35.

Martín Ruiz, J. F. (2016): Dependencia, pobreza y población en África. Los problemas del desarrollo humano. Madrid: Mercurio.

Martínez-Buján, R. (2015): Gendered motivations for return migration to Bolivia from Spain”. Journal of Immigrant and Refugee Studies, 13 (4), pp. 401-418.

Massey, D. et al. (1987). Return to Aztlan. Berkeley: University of California Press.

Massey, D. et al. (1993): Theories of International Migration: A Review and Appraisal. Population and Development Review, 3, pp. 431-466.

Massey, D., Durand, J. y Goldring, L. (1994): Continuities in Transnational Migration: An Analysis of 19 Communities. American Journal of Sociology, 99(6), pp. 1492-1533.

Massey, D. y Espinosa, K. (1997): What's driving Mexico-US Migration? A Theoretical, Empirical and policy Analysis. American Journal of Sociology, 102, pp. 939-999.

Massey, D., Arango, J., Graeme, H., Kouaduci, A., Pellegrino, A. y Taylor, J. E. (2000): Teorías sobre la migración internacional: una reseña y una evaluación. Trabajo, Migraciones y mercados de trabajo, año 2, núm. 3, México, UNAM

Massey, D., Durand, J. y Malone, N. (2003): Beyond smoke and mirrors: Mexican immigration in an era of economic integration. New York: Russel Sage Foundation.

Medina, E., Herrarte, A. y Vicéns, J. (2010): Inmigración y desempleo en España: impacto de la crisis económica. Revista de economía 854, pp. 37-48. 
Mendoza, C., Staniscia, B. y Ortiz Guitart, A. (2016): Migración y movilidad de las personas calificadas: nuevos enfoques teóricos, territorios y actores. Biblio3W Revista bibliográfica de Geografía y Ciencias Sociales. Universidad de Barcelona. Vol. XXI, 1.166.

Núñez SEIXAs, X. M. (2000): Emigración de retorno y cambio social en la Península Ibérica. Algunas observaciones teóricas en perspectiva comparativa. Migraciones y Exilios, Cuadernos de la AEMIC, 1, pp. 27-66.

Organización de Estados Iberoamericanos. Consultado el 15 de diciembre de 2016 (www.oei.es)

Organización para las Migraciones Internacionales (2012): Annual Report of Activities 2011. Ginebra: Ed. I.M.O.

Parella, S. (2003): Mujer, inmigrante y trabajadora: La triple discriminación. Anthropos Editorial.

Pascual de Sans, A. (1983): Los movimientos migratorios de retorno, significación y perspectivas. Documents d'Análisi Geográfica, 3, pp. 47-69

Pérez Caramés, A. (2012): El retorno de los migrantes rumanos: inversión de remesas y ahorros y estrategias de reintegración. En Mourad ABoussi (Coord.). El codesarrollo a debate. Granada: Editorial Comares, pp. 71-85.

Petit, A. (2002): Una mirada a la comunidad china desde Occidente. Cuadernos de Geografía, 72, pp. 321-336.

Portes, A. y Bachs, R. (1985): Latin Journey. Berkeley: California University Press.

ReCAÑo, J. y JAÚREgUi, J. A. (2014): Emigración exterior y retorno de latinoamericanos desde España: una visión desde las dos orillas (2002-2012). Notas de Población, 99, pp. 177-240.

Reyes, B. (1997): Dynamics of inmigration: Return migration to Western Mexico. San Francisco: Public Policy Institute of California.

Rivera, L. (2013): Migración de retorno y experiencias de reinserción en la zona metropolitana de la ciudad de México. Rev. Interdiscipl. Mobil. Hum., XXI, 41, pp. 55-76.

Rodríguez, V. \& EgeA, V. (2006): Return and the Social Environment of Andalusian Emigrants in Europe. Journal of Ethnic and Migration Studies, 32(8), pp. 1377-1393.

SAMPEDRO, R. y CAMARERO, L. (2016): Inmigrantes, estrategias familiares y arraigo: las lecciones de la crisis en las áreas rurales. Revista Migraciones, 40, pp. 3-31.

SAssen, S. (1999): Guest and Aliens. New York: The New York Press.

Schramm, C. (2011): Retorno y reinserción de migrantes ecuatorianos. La importancia de las redes sociales transnacionales. CIDOB d'Afers Internacionals, 93-94, pp. 241-260.

Todaro, M. (1969): A model of Labour Migration and urban employment in less development countries. The American Economic Review, 59 (1), pp. 138-148.

VAlLÉs, M. S. (2005): Metodología y tecnología cualitativas: actualización de un debate, desde la mirada más atenta en la obra de Barney G. Glaser. Empiria, 9 (enero-junio), pp. 145-168. 
Varona, M. y Daolio, N. (1995): De vuelta a casa. Ministerio de Asuntos Sociales. Dirección General de Migraciones.

Vega Solís, C. y Martínez-Buján, M. (2016): Las migraciones de retorno de la población ecuatoriana y boliviana: motivaciones, estrategias y discursos. Investigaciones feministas, 7 (1), pp. 265-287.

Vega Solis, C., Gómez Martín, C. y Correa, A. (2016): Circularidad migratoria entre Ecuador y España. Transformación educativa y estrategias de movilidad. Migraciones, 39, pp. 183-210.

YANG, D. (2004): Why Do Migrants Return to Poor Countries? Evidence from Philippine Migrants' Responses to Exchange Rate Shocks. Discussion Papers Series, 2004, pp. 1-56. Michigan: The University of Michigan Ann Arbor. 